\title{
Are there solutions on the horizon for plastics recycle?
}

\author{
Subhas Sikdar ${ }^{1}$ \\ Published online: 5 August 2020 \\ (c) Springer-Verlag GmbH Germany, part of Springer Nature 2020
}

From mid-eighties well into the nineties of the last century, various Government agencies in the USA were engaged in a strategic planning, called Vision 2020. This effort led to an avalanche of similar planning exercise by research institutes, local governments, with appropriate reports issued. Many other nations launched Vision 2020 planning as well. The main focus was to take stock of the then issues involving energy, materials, water, and production practices, and envision a more sustainable state in 2020 with specific targets to achieve using current and prospective technological and regulatory methods. The US Department of Energy has relaunched a planning exercise for moving beyond from here to 2030 , with similar identified markers to achieve. One of the objectives of these efforts was to stimulate extensive plastics recycle and reuse.

Plastics recycle and reuse research efforts had actually started in the early seventies in a modest way, years before the concerted efforts stimulated by Vision 2020. Much of the recyclable plastic wastes emanated from consumer products, consequently curbside pickup started and eventually spread to all metropolitan areas of the USA. Europe started this pickup service earlier than the USA, however. The citizens were asked to believe that the collected waste material will end up in products that would be used again in the economy, reducing the need for virgin materials. In the late eighties, I had an opportunity to listen to an invited talk by a representative of a large German automotive manufacturer at a conference in Taiwan. Much to my disappointment, I found out that the much of what was presented amounted to separating plastic wastes for energy recovery by incineration. Given that the most undesirable outcome is landfilling, energy recovery by thermal means may be somewhat superior, but it is certainly below what was generally expected by the public. Three decades later, plastics recycle/reuse still suffers from the intended

Dr. Subhas Sikdar is the Editor-in-Chief.

Subhas Sikdar

subhas.sikdar@gmail.com

1 Cincinnati, USA goal of repurpose for products to be used for consumer products, mostly in packaging. A broad definition of recycle would mean using the waste plastics for application in products of lower value. Recovered energy from plastics can be included in this definition. Reuse on the other hands generally would imply repurposing the waste for the same application as that of the original product. There are three classes of plastic products, by and large. First, thermoplastics such as polyolefins and polystyrenes degrade in polymer chain length during thermal treatment, with consequent degradation of physical and mechanical properties. They are also harder to recover in pure form from formulations that contain other constituents such as plasticizers, colors, and modifiers. Second, condensation polymers, such as polyesters and nylons, on the other hand, can be hydrolyzed chemically to yield the constituent comonomers back. After purification of the individual monomers, virgin polymers can be made from these wastes. In the circular process of getting the monomers back, there is no property hysteresis for these polymers, whereas thermoplastics do suffer from such hysteresis. The third class, called thermosets, is purposefully cross-linked to give the products toughness, rigidity, water, and chemical resistance. These products, such as phenol-formaldehyde and melamine-based plastics, are even harder than thermoplastics to recycle. Energy recovery may be a desired solution for these.

Environmental concerns about plastics mostly result from dispersion of consumer products in the environment. Packaging materials that are tossed at the roadsides and in green areas were a big concern before but are probably less so now because of increased public awareness of the environmental impacts of these irresponsible practices. But plastics in the waterways, particularly in oceans are a big concern still. It has been estimated that by 2050, the mass of waste plastics in the ocean will exceed that of fish. ${ }^{1}$ Microplastics, a newer concern, are believed to be injurious to marine life. They also accumulate at the sea floor, ${ }^{2}$ and transport through the atmosphere over vast distances. ${ }^{3}$

\footnotetext{
1 C\&E News, March 19, 2018, p. 17

2 Science, 5 June 2020, p. 1055).

${ }^{3}$ C\&E News, July 15, 2020.
} 
Fig. 1 Historical record of end of life of waste plastics in the USA

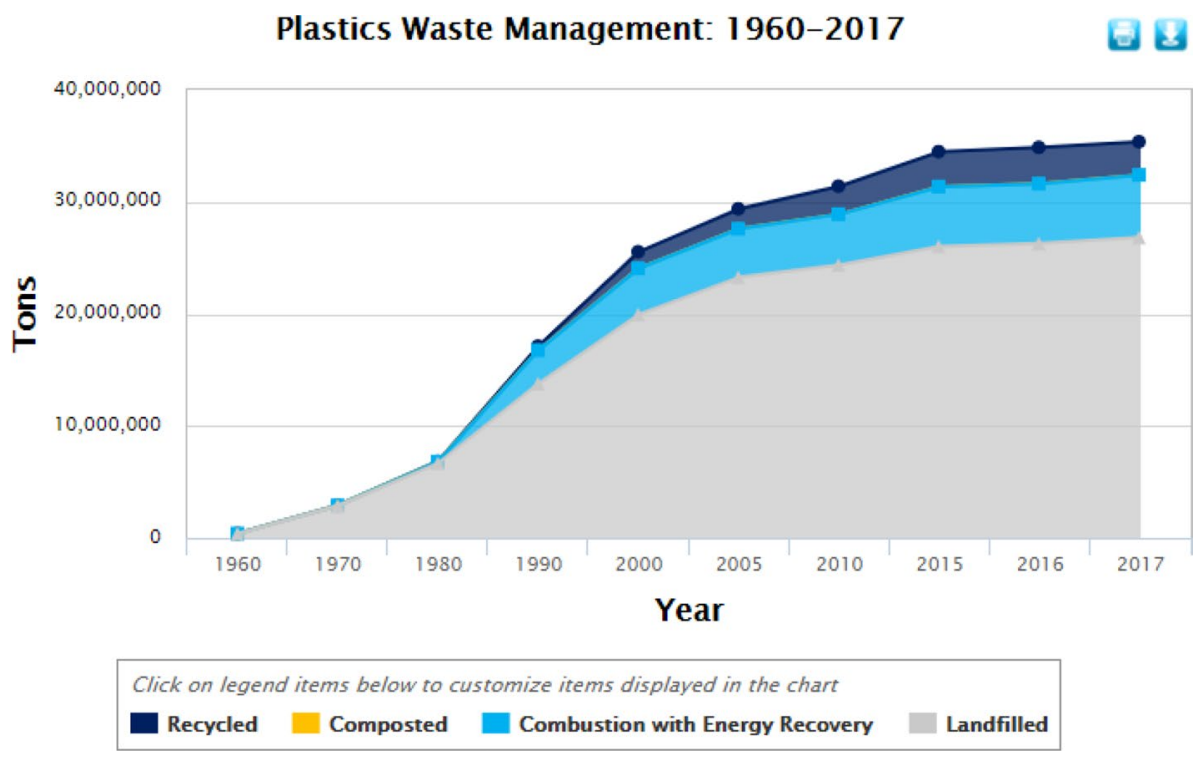

Once dispersed in the environment, much nuisance is created by waste plastics. To avoid dispersion, careful collection and sorting is required. In the USA, most municipal waste companies collect plastics from curbside mixed with all kinds of other recyclable materials, such as paper and metals. What happens after collection is anybody's guess. The recycle vendors are responsible for managing the sorting in a municipal recycle facility (MRF), and the management of the recycle practice depends on local regulations. Much improvement is needed in this area, for instance, by separating plastics from other recyclable materials at pickup.

A tremendous amount of waste plastics from US municipalities used to be sold to China. Chinese were willing buyers until recently. With the Chinese markets thus unavailable, in the short term, at least in the USA, landfilling appears to be an easy fallback, as long as it is the cheapest. The MRFs prefer nothing more than polyethylene terephthalate, highdensity polyethylene, and polypropylene. ${ }^{4}$ The others are currently destined for landfills.

Despite all the hype about plastics recycle/reuse in the past, little was actually accomplished. The current situation is very unsatisfactory indeed. The US Environmental Agency data show the meager degree of success we have achieved in all these years from 1960 to 2017 . This is shown in Fig. 1. ${ }^{5}$

As is evident from Fig. 1, the overwhelming portion of the waste plastics is not recycled at all; they are merely buried for posterity. Most of these plastics are derived from petroleum feedstocks, and do not degrade in the landfill at

\footnotetext{
$\overline{4}$ C\&E News, Sept 24, 2018.

5 https://www.epa.gov/facts-and-figures-about-materials-waste-andrecycling/plastics-material-specific-data.
}

any rates that can be called desirable. Much work needs to be done if the volume of plastics going to landfill is to be drastically reduced. European Union recently pledged to achieve $55 \%$ plastics packaging recycling by 2030 from a current level of only $5 \%{ }^{6}$

The desired hierarchy of plastics recycle/reuse should be in this order:

- Re-convert the waste to constituent monomers to enable true recycle for reuse. The technological methods of depolymerization can be thermal methods, or solution methods.

- Convert to lower-grade plastics to be used as products. Park benches, road dividers, plastic bags are examples of such applications.

- Derive energy if none of the former is feasible, either technologically, or economically. One option is incineration. Alternatively, pyrolysis can produce bio-oil, which on refinement may be used as a transportation fuel.

- Landfill as the last resort.

The above hierarchy of course is applicable to fossil fuelderived plastics. For at least four decades, alternatives to this source have been researched so as to create substitutes for petroleum with biomass. The driver for this approach is the belief that bio-based polymers are naturally biodegradable. However, this generalization often does not meet satisfaction. Nowadays, researchers are pondering about designing biodegradability in the formulation.

The Japanese were early forerunners on research on bio-based polymers such as polyhydroxyalkanoates.

\footnotetext{
${ }^{6}$ C\&E News, Sept. 30, 2019, p. 11.
} 
Constitutionally, these polymers are like polyesters. But the properties of these polymers did not measure up, resulting in little penetration in the market. In the USA, however, polylactic acid (PLA) earned early success in commercialization in some applications. More recent events show other more versatile possibilities—synthesizing familiar polymers from bio-derived chemicals, such as ethanol. Thus, ethanol can be converted to ethylene, ethylene glycol, even to isoprene, propylene, and terepthalic acid. ${ }^{7}$ Lactic acid can be converted to acrylic acid. An entire suite of chemicals for various applications is now seen possible through biological methods. Additionally, even cellulose can be fashioned to replace petroleum-based polymers in some applications. ${ }^{8}$
Thus, we arrive at a spot to highlight biomass utilization for substituting petroleum-based polymers and plastics. However, whether or not petroleum-derived polymers and chemicals can be significantly replaced, in the short or long term, to make a difference in overall GHG emissions remain to be seen. It is not also clear if this is a desirable thing to do from a resource management viewpoint. In the next issue of this journal, we will publish two papers that examine this question from holistic ecological and energy management viewpoints.

Subhas Sikdar

Editor in Chief

\footnotetext{
7 Science, 17 Nov, 2017, p. 869.

8 Scientific American, December 2019, p. 28.
} 